\author{
Marquette University \\ e-Publications@Marquette
}

College of Communication Faculty Research

and Publications

Communication, College of

$4-2010$

\title{
Symptom Information in Direct-to-Consumer Antidepressant Advertising and College Students' Perception of the Lifetime Risk Depression
}

Jin Seong Park

Temple University

Jean M. Grow

Marquette University, jean.grow@mu.edu

Follow this and additional works at: https://epublications.marquette.edu/comm_fac

Part of the Communication Commons

\section{Recommended Citation}

Park, Jin Seong and Grow, Jean M., "Symptom Information in Direct-to-Consumer Antidepressant Advertising and College Students' Perception of the Lifetime Risk Depression" (2010). College of Communication Faculty Research and Publications. 26.

https://epublications.marquette.edu/comm_fac/26 


\title{
Symptom Information in Direct-To- Consumer Antidepressant Advertising and College Students' Perception of the Lifetime Risk of Depression
}

\author{
Jin Seong Park \\ A Department of Advertising, Temple University \\ Philadelphia, PA \\ Jean M. Grow \\ Associate Professor, Marquette University \\ Milwaukee, WI
}

\begin{abstract}
:
While consumers' health cognition and behavior are likely formed through multiple influences, the current study focused on the effects of exposure to specific content elements in direct-to-consumer advertising. The study revealed that consumers' exposure to the American Psychiatric Association's (APA) diagnostic guideline has potential to reduce their perceived lifetime risk of depression and intention to consult a health professional to discuss the health issue. The study further revealed when an antidepressant ad mentioned a long list of symptoms, exposure to the diagnostic guideline reduced risk perception and consultation intention
\end{abstract}


NOT THE PUBLISHED VERSION; this is the author's final, peer-reviewed manuscript. The published version may be accessed by following the link in the citation at the bottom of the page.

significantly, whereas in the presence of a short list of symptoms, the APA guideline had minimal impact.

\section{Introduction}

A large body of research shows direct-to-consumer (DTC) prescription drug advertising has strong potential to influence consumers' health cognition and behavior. For instance, Iizuka and Jin ${ }^{1}$ reported the pharmaceutical industry's DTC advertising expenditure predicted an overall increase in consumer visits to doctors' offices. Similarly, Donohue and Berndt ${ }^{2}$ found the industry expenditure on DTC antidepressant advertising led to an increase in the number of patient requests for antidepressant treatment. When doctors refuse to prescribe the requested drugs, patients tend to be dissatisfied and insist on prescriptions for the drugs they saw from the advertisements. $^{3}$

Although the literature suggests DTC advertising has power to spur the expansion of a drug brand or category, research has predominantly focused on revealing how consumers ' overall exposure to a category of DTC advertising influences their beliefs, attitudes and behavior regarding health issues. There is a paucity of research attributing such cognitive and behavioral effects to consumer exposure to specific content elements strategically placed in pharmaceutical ads. Without research accounting for how consumers process and respond to specific information categories in prescription drug ads, the literature would present limited insights for the practice of DTC advertising. The current study addresses this limitation by exploring how exposure to specific categories of information in DTC ads influences consumer perception of diseases.

Considering depression is increasingly prevalent among young adults ${ }^{4}$ and consumer socialization begins at early life stages, ${ }^{5}$ the current study is designed to explore how college students ' perception of clinical depression is influenced by the information DTC antidepressant advertisements present regarding the symptoms of clinical depression. More specifically, we expect college students' estimation of their lifetime risk of depression and intention to consult a health professional to discuss the health issue will be influenced by: (1) the number of depression symptoms listed in the ad; (2) the type of depression symptoms mentioned in the ad; and (3) whether the ad

Journal of Medical Marketing, Vol. 10, No. 2 (April 2010): pg. 123-133. DOI. This article is C Palgrave Macmillan and permission has been granted for this version to appear in e-Publications@Marquette. Palgrave Macmillan does not grant permission for this article to be further copied/distributed or hosted elsewhere without the express permission from Palgrave Macmillan. 
provides a guideline about the way consumers should use the symptom information to assess their health appropriately.

Of many potentially important diseases, the current study focuses on depression for the reason that although antidepressants are one of the most heavily advertised prescription drug categories in the DTC market, ${ }^{6}$ depression remains largely under-diagnosed and undertreated. ${ }^{7}$ This study will illuminate how antidepressant ads can be used to influence consumer perception of the future risk of depression. Considering high risk perception has potential to spur preventive and remedial health behavior, ${ }^{8}$ the findings of this study will produce insights into how advertising practitioners can use DTC advertising in an effective and socially responsible way to expand the antidepressant market and help reduce the under-treatment of depression.

\section{Theoretical Framework}

Information on the symptoms of a disease frequently appears in DTC advertising. Antidepressant ads, for instance, typically present the symptoms of clinical depression, such as sleep disorders and difficulty with thinking. However, the ads present such symptoms in a variety of ways. For example, after listing a wide range of depression symptoms, an ad for Zoloft states that to be considered indicative of clinical depression, the symptoms must interfere with one 's daily life and last each day over a two-week period. This instruction is equivalent to the American Psychiatric Association's (APA) ${ }^{9}$ guideline for the accurate diagnosis of depression. In comparison, an ad for Effexor XR mentions only one symptom, 'wanting to be alone', without further symptomrelated information.

Differences in the way antidepressant ads present the symptoms of depression are expected to influence consumer perception of the future risk of depression. The principle of representativeness heuristic ${ }^{10}$ suggests consumers will report a higher subjective risk of depression as they perceive their life experiences to be more similar to the experiences of typical depression patients. Information on the symptoms of depression has potential to influence risk estimation by altering consumers ' mental prototype of depression patients, ${ }^{11}$ which in turn will affect the perceived similarity between their own and the typical patients ' life experiences. The power of 
symptom information to influence risk perception is rooted in consumers ' tendency to heuristically assume the presented symptoms represent the population of depression symptoms. ${ }^{10}$

The principle of representativeness heuristic leads to the expectation that consumer perception of the lifetime risk of depression will be influenced by the number of depression symptoms listed in an antidepressant ad and exposure to an APA-type diagnostic guideline. The APA9 suggests that, to be considered indicative of clinical depression, one's experiences of the symptoms of depression should last nearly every day over a two-week period. Therefore, the guideline does not permit the inference that one is depressed based on observation of the symptoms for a day or a few days. For this reason, exposure to the guideline has potential to reduce the perceived lifetime risk of depression by decreasing the degree to which individuals perceive their life experiences to resemble those of typical depression patients.

However, exposure to the APA guideline will have stronger effects on risk perception when the ad presents a long list of symptoms, compared to when fewer symptoms are listed. This is because, given the guideline that observation of symptoms for a few days does not indicate depression, exposure to a large amount of symptom information would further corroborate one's initial judgment that the future risk of depression would be low. ${ }^{11}$ In contrast, the APA guideline would have significantly reduced impact on risk perception when a smaller amount of symptom information is presented.

Therefore, we hypothesize that when the ad presents a long list of symptoms, exposure to the APA guideline will significantly decrease the perceived lifetime risk of depression. In contrast, in the presence of a short list of symptoms, the APA guideline will have minimal impact on risk perception (H1). Once formed, risk perception is a strong determinant of consumer engagement in preventive and remedial health behaviors. ${ }^{8,12,13}$ Therefore, we hypothesize that the APA guideline and the number of symptoms will influence consumer intention to consult a health professional to discuss depression in the same pattern as they affect risk perception $(\mathrm{H} 2)$.

Journal of Medical Marketing, Vol. 10, No. 2 (April 2010): pg. 123-133. DOI. This article is (c) Palgrave Macmillan and permission has been granted for this version to appear in e-Publications@Marquette. Palgrave Macmillan does not grant permission for this article to be further copied/distributed or hosted elsewhere without the express permission from Palgrave Macmillan. 
Similar to exposure to the APA guideline, the type of depression symptoms presented in the ad will also interact with the number of symptoms to influence risk perception. Following Menon et al, ${ }^{11}$ the current study categorizes the symptoms of depression into: (a) common symptoms, defined as the symptoms that subjects experience relatively frequently in their lives; and (b) uncommon symptoms, namely the symptoms subjects experience less frequently.

Exposure to common symptoms would lead to the judgment that one's own life experiences resemble those of typical depression patients, and therefore has potential to raise the perceived risk of depression, whereas uncommon symptoms would have the opposite effects. ${ }^{11}$ In addition, the effects of symptom type (that is, common versus uncommon) will be stronger when the ad presents a long list of symptoms than when fewer symptoms are listed. This is because, once exposed to a particular type of symptoms, receiving more symptoms of the same category will corroborate one's initial judgment of the future risk of depression. ${ }^{11}$

Therefore, we hypothesize that when the ad presents a long list of symptoms, exposure to common symptoms will result in a significantly higher perceived lifetime risk of depression than exposure to uncommon symptoms. In contrast, with a short list of symptoms, exposure to common versus uncommon symptoms will produce a minimal difference in risk perception (H3). We further expect the number and type of symptoms to have the same interactive effects on consultation intention $(H 4)$.

\section{Method}

\section{Design}

A 2 (number of symptoms: two versus five) $\times 2$ (exposure to the APA guideline: present versus absent) $\times 2$ (type of symptoms: common versus uncommon) between-subjects design was employed with a non-factorial control group. Because a moderate correlation was expected between risk perception and consultation intention, multivariate analysis of variance (MANOVA) was used as the main method of hypotheses testing. Follow-up tests of simple effects were conducted for exploratory purposes. 
NOT THE PUBLISHED VERSION; this is the author's final, peer-reviewed manuscript. The published version may be accessed by following the link in the citation at the bottom of the page.

\section{Subjects and Procedure}

A total of 318 undergraduates enrolled in introductory advertising courses at a southern state university participated in return for course credit. Fifteen subjects reported they had experienced clinical depression. Because the question to measure the perceived lifetime risk of depression (that is, 'what are the chances that you will suffer from depression during your lifetime?') was considered irrelevant to those who had already experienced depression, the 15 subjects were deleted from further analysis. Of the remaining 303 subjects, 66.7 percent were females, and the average age was 20.23 $(\mathrm{SD}=2.16)$. The majority were whites (74.3 percent), followed by Hispanics (10.6 percent), Asian Americans (7.6 percent), and African Americans (5.6 percent).

Sessions were conducted in a laboratory. Subjects participated in groups of 5 to 25 . To differentiate clinical depression from temporary mood swings, subjects were instructed that 'clinical depression is defined in this project as a form of medical illness that may require doctor's intervention for treatment'. Then subjects were randomly assigned to the nine experimental groups. It took approximately 15 min to complete the instrument. Upon completion of the instrument, subjects were thanked and debriefed.

\section{Stimulus}

A pretest was conducted to select the five common and uncommon symptoms of depression. A total of 29 symptoms were compiled from widely cited measures of depression. ${ }^{9,14}$ Subjects $(N=$ 45) reported on a seven-point scale ( 1 =never, 7 =very frequently) how frequently they experienced the symptoms. The five common symptoms selected were sleep disorders, feeling tired for no reason, restlessness, difficulty with thinking and inability to make decisions. The five uncommon symptoms were feeling hopeless about the future, feeling one' $s$ life is empty, inability to enjoy the things one used to do, feeling guilty or worthless, and having acquaintances notice that one is restless.

The number and type of depression symptoms and exposure to the APA guideline were manipulated between subjects by exposing 
them to different versions of information about a fictitious antidepressant brand. Similar to Davis, ${ }^{15}$ the study was introduced as a copy-test for a new advertising campaign for an antidepressant brand recently released by an unnamed pharmaceutical company. Accordingly, the stimulus was disguised as the body copy of the advertisement. The following is the stimulus assigned to the group that received two common symptoms of depression with the APA guideline. The copy was equal across the eight treatment groups except for the italicized part, where manipulations occurred.

You have trouble sleeping through the night ... You get tired for no reason ... If these last nearly every day for two weeks, they are symptoms of depression. Some may say it's 'just in your head.' But depression is a serious illness with real medical causes. While the causes are unknown, depression is related with an imbalance of chemicals in the brain. Clinical studies prove that Celsta can effectively correct this imbalance and relieve symptoms of depression. Celsta is not for everyone. It is approved for adults 18 and over. People taking MAOIs should not take Celsta. Side effects may include dry mouth, dizziness, insomnia, delayed ejaculation, diarrhea, anorexia, and sleepiness. Celesta is a prescription drug. Talk to your doctor about Celsta. Get a free educational DVD about depression and Celsta by calling 1-800-6-Celsta, or visiting YouNeedNewLife.com .

\section{Measures}

\section{Type of Symptoms (Common versus Uncommon)}

The type of symptoms was manipulated between subjects by assigning them to common or uncommon symptoms of depression. Although the number of symptoms listed in the stimulus varied between two and five, for the purpose of checking the manipulation, subjects reported their experiences with the five common or uncommon symptoms after completing the dependent measures.

The manipulation was checked separately for the subjects who received the APA guideline $(n=137)$ and those without the guideline $(n=136)$. In response to the five common or uncommon symptoms, subjects without the APA guideline $(n=137)$ answered the following question on a seven-point scale ( $1=$ never, $7=$ very frequently): 'In 
your life these days, how often do you have the following feelings / experiences?' Responses to the five symptoms were averaged into a symptom frequency index.

For the same common or uncommon symptoms, subjects exposed to the APA guideline $(n=136)$ answered the following question on a seven-point scale ( $1=$ not likely at all, 7 =very likely): 'Looking back on your life these days, how likely would it be that you have the following feelings / experiences nearly every day for a given two-week period? ' Responses to the five symptoms were averaged into a symptom likelihood index.

\section{Perceived Lifetime Risk of Depression}

Subjects answered in percentage the following single-item question: 'What are the chances that you will suffer from depression during your lifetime?' The non-factorial control group rated the lifetime risk to be 19.17 on the average ( $S D=18.88)$. Notably, males and females did not significantly differ in their risk perception ( $M_{\text {males }}=$ $\left.17.83, \mathrm{SD}=23.53 ; M_{\text {females }}=20.06, \mathrm{SD}=15.74\right)$, while epidemiological studies indicate the actual lifetime risk is approximately 25 percent for women and 12 percent for men. ${ }^{16,17}$

\section{Intention for Consultation}

Subjects indicated on a seven-point scale ( 1 = strongly disagree, $7=$ strongly agree) their agreement with the following statement: 'If the University Health Services offered free consultation about depression, I would intend to participate to know more about depression or Celsta', similar to the single-item scale used by Raghubir and Menon. ${ }^{18}$ Because the non-factorial control group was not exposed to any antidepressant brand, the fictitious brand name was replaced with ' antidepressants ' in the statement for the group. Males and females did not differ in their consultation intention $\left(M_{\text {males }}=3.17\right.$, $\left.\mathrm{SD}=1.53 ; M_{\text {females }}=3.37, \mathrm{SD}=1.54\right)$, a result in sync with a minimal gender difference in risk perception.

Journal of Medical Marketing, Vol. 10, No. 2 (April 2010): pg. 123-133. DOI. This article is (C) Palgrave Macmillan and permission has been granted for this version to appear in e-Publications@Marquette. Palgrave Macmillan does not grant permission for this article to be further copied/distributed or hosted elsewhere without the express permission from Palgrave Macmillan. 


\section{Perceived Symptom Representativeness}

A vital assumption of the principle of representative heuristic is that consumers assume the presented symptoms represent the population of depression symptoms. ${ }^{10}$ To check if this assumption is valid in the sample, subjects checked on a seven-point scale ( 1 = not representative at all, $7=$ highly representative) how representative a series of experiences were of the symptoms of depression. The experiences were the depression symptoms used to manipulate symptom type. Subjects without the APA guideline $(n=136)$ reported their judgments on the five common or uncommon symptoms. Subjects with the APA guideline $(n=137)$ reported how representative it was to experience the five common or uncommon symptoms' nearly every day for a given two-week period'. Responses were averaged into a symptom representativeness index.

\section{Results}

\section{Manipulation Check}

For the subjects with no exposure to the APA guideline, the symptom frequency index was submitted to a 2 (number of symptoms: two versus five) $\times 2$ (type of symptoms: common versus uncommon) factorial ANOVA. As desired, the type of symptoms had a significant main effect on the frequency index $\left[M_{\text {common }}=3.37, S D=\right.$ $1.14 ; M_{\text {uncommon }}=2.27, \mathrm{SD}=1.10, F(1,132)=33.09, P<0.001, n_{p}^{2}=$ $0.20]$, while no other significant main or interaction effect was observed.

For the subjects exposed to the APA guideline, we conducted a 2 (number of symptoms: two versus five) $\times 2$ (type of symptoms: common versus uncommon) factorial ANOVA on the symptom likelihood index. The results indicated that the type of symptoms had a significant main effect on the likelihood index $\left[M_{\text {common }}=2.55, \mathrm{SD}=\right.$ $1.25 ; M_{\text {uncommon }}=1.59, \mathrm{SD}=0.68, F(1,133)=32.20, P<0.001, n_{p}^{2}=$ $0.20])$. As desired, no other significant main or interaction effect was observed, implying the manipulation was successful. 


\section{Symptom Representativeness}

To test whether consumers assume the presented symptoms represent the population of depression symptoms regardless of symptom type and exposure to the APA guideline, the symptom representativeness index was submitted to a 2 (number of symptoms: two versus five) $\times 2$ (exposure to the APA guideline: presence versus absent) $\times 2$ (type of symptoms: common versus uncommon) factorial ANOVA. The results showed exposure to the APA guideline did not have a significant main effect on the representativeness index [ $M_{\mathrm{APA}}=$ $4.64, \mathrm{SD}=1.89 ; M_{\mathrm{nOAPA}}=4.50, \mathrm{SD}=1.65, F(1,264)=5.82, P=$ $0.45]$. However, symptom type had a significant main effect $\left[M_{\text {common }}=\right.$ 4.05, $\mathrm{SD}=1.68 ; M_{\text {uncommon }}=5.06, \mathrm{SD}=1.73, F(1,264)=24.17, P<$ $0.001]$, violating a vital assumption of the principle of representativeness heuristic. This led to the expectation that $\mathrm{H} 3$ and H4 might not be supported. No other main or two-way interaction effects were significant. However, the three-way interaction was significant $[F(1,264)=6.45, P=0.01]$.

\section{$H 1$ and $H 2$}

Hypotheses 1 and 2 were designed to examine the interactive effects of the number of symptoms and exposure to the APA guideline on subjects' perceived lifetime risk of depression and consultation intention. The two hypotheses were tested by conducting a 2 (number of symptoms: two versus five) $\times 2$ (exposure to the APA guideline: present versus absent) $\times 2$ (type of symptoms: common versus uncommon) MANOVA on risk perception and consultation intention. The assumption of homogeneous variance-covariance matrices was satisfied [Box's $M=29.18, F(21,245417)=1.36, P=0.13$ ].

The MANOVA results revealed the number of symptoms $\times$ exposure to the APA guideline interaction was significant (see Table 1), indicating the effects of the APA guideline on risk perception and consultation intention were moderated by the amount of symptom information. The three-way interaction was not significant, indicating the significance of the two-way interaction did not depend on the type of symptoms.

Journal of Medical Marketing, Vol. 10, No. 2 (April 2010): pg. 123-133. DOI. This article is (C Palgrave Macmillan and permission has been granted for this version to appear in e-Publications@Marquette. Palgrave Macmillan does not grant permission for this article to be further copied/distributed or hosted elsewhere without the express permission from Palgrave Macmillan. 
The MANOVA results would be invalidated if the number of symptoms $\times$ exposure to the APA guideline interaction had differential effects on risk perception and consultation intention. If the effects significantly differed, conducting ANOVAs for testing $\mathrm{H} 1$ and $\mathrm{H} 2$ separately would be more appropriate than using a MANOVA for testing the two hypotheses simultaneously. To check this possibility, a four-way mixed MANOVA was designed, entering the three independent variables as between-subjects factors and risk perception and consultation intention as a within-subjects factor. For comparability, scores on risk perception and consultation intention were Z-transformed.

As Table 2 shows, the three-way interaction of exposure to the APA guideline, number of symptoms and the within-subject factor was not significant. This ruled out the possibility that the number of symptoms $\times$ the APA guideline interaction might have differential effects on risk perception and consultation intention. Therefore, followup ANOVAs were not necessary.

Analyses of simple effects further revealed the interaction largely occurred in such a pattern as specified in $\mathrm{H} 1$ and $\mathrm{H} 2$. Among subjects who received common symptoms, when the ad listed two symptoms, exposure to the APA guideline did not produce a significant difference in risk perception $\left[t(62.99)=0.32, P=0.75, M_{\text {two-common- }}\right.$ noAPA $\left.=27.52, \mathrm{SD}=25.98 ; M_{\mathrm{two}-\text { common-APA }}=29.53, \mathrm{SD}=25.47\right]$ or consultation intention $\left[t(294)=1.57, P=0.12, M_{\text {two-common-noAPA }}=2.15\right.$, $\left.\mathrm{SD}=1.28 ; M_{\text {two-common-APA }}=2.72, \mathrm{SD}=1.75\right]$. In contrast, when five symptoms were presented, the APA guideline significantly reduced risk perception $\left[t\left(62.35=2.45, P=0.02, M_{\text {five-common-noAPA }}=33.82, \mathrm{SD}=\right.\right.$ 25.08; $M_{\text {five-common-APA }}=20.19$, SD $\left.=20.77\right]$ and consultation intention $\left[t(294)=2.07, P=0.04, M_{\text {five-common-noAPA }}=2.73, \mathrm{SD}=1.35 ; M_{\text {five-common- }}\right.$ $\mathrm{APA}=2.00, \mathrm{SD}=1.35]$.

A similar pattern was observed among subjects who received uncommon symptoms. When the ad presented two symptoms, exposure to the APA guideline did not significantly reduce risk perception $\left[t(56.59)=1.10, P=0.28, M_{\text {two-uncommon-noAPA }}=19.89, \mathrm{SD}=\right.$ $\left.18.47 ; M_{\text {two-uncommon-APA }}=25.91, \mathrm{SD}=26.32\right]$ or consultation intention $\left[t(294)=1.05, P=0.29, M_{\text {two-uncommon-noAPA }}=2.22, \mathrm{SD}=1.58 ; M_{\text {two- }}\right.$ uncommon-APA $=1.85, S D=1.35]$. In contrast, when five symptoms were 
presented, the APA guideline significantly reduced consultation intention $\left[t(294)=2.73, P=0.007, M_{\text {five-uncommon-noAPA }}=3.15, \mathrm{SD}=\right.$ $\left.1.58 ; M_{\text {five-uncommon-APA }}=2.19, \mathrm{SD}=1.43\right]$. The APA guideline reduced risk perception, but the reduction did not reach statistical significance [ $t(64.31)=1.11, P=0.27, M_{\text {five-uncommon-noAPA }}=26.33, \mathrm{SD}=22.47 ; M_{\text {five }}$ uncommon-APA $=20.64, \mathrm{SD}=19.98]$.

\section{$H 3$ and $H 4$}

Hypotheses 3 and 4 were designed to examine the effects of the number of symptoms and the type of symptoms on perceived lifetime risk of depression and consultation intention. Table 1 shows the number $\times$ type of symptoms interaction was not significant, indicating the effects of symptom type on the two dependent variables did not depend on the amount of symptom information. Therefore, $\mathrm{H} 3$ and $\mathrm{H} 4$ were not supported. Table 1 also shows the three-way interaction was not significant, implying the non-significance of the number $\times$ type of symptoms interaction did not depend on whether subjects received the APA guideline or not. Further, the effects of the number $\times$ type of symptoms interaction were not moderated by the within-subject factor (see Table 2), indicating the two-way interaction had equivalent effects on risk perception and consultation intention.

Analyses of simple effects also revealed the effects of symptom type on risk perception and consultation intention were equivalent whether the ad presented two or five symptoms. Among subjects with no exposure to the APA guideline, when the ad presented two symptoms, exposure to common symptoms did not produce higher risk perception $\left[t(57.06)=1.40, P=0.17, M_{\text {two-common-noAPA }}=27.52, \mathrm{SD}\right.$ $\left.=25.98 ; M_{\text {two-uncommon-noAPA }}=19.89, \mathrm{SD}=18.47\right]$ or stronger consultation intention $\left[t(294)=0.19, P=0.85, M_{\text {two-common-noAPA }}=\right.$ $\left.2.15, \mathrm{SD}=1.28 ; M_{\text {two-uncommon-noAPA }}=2.22, \mathrm{SD}=1.58\right]$ than exposure to uncommon symptoms. Similarly, when five symptoms were presented, the type of symptoms did not lead to a significant difference in risk perception $\left[t(63.24)=1.28, P=0.21, M_{\text {five-common- }}\right.$ noAPA $\left.=33.82, \mathrm{SD}=25.08 ; M_{\text {five-uncommon-noAPA }}=26.33, \mathrm{SD}=22.47\right] \mathrm{or}$ consultation intention $\left[t(294)=1.18, P=0.24, M_{\text {five-common-noAPA }}=2.73\right.$, $\left.\mathrm{SD}=1.35 ; M_{\text {five-uncommon-noAPA }}=3.15, \mathrm{SD}=1.58\right]$.

Journal of Medical Marketing, Vol. 10, No. 2 (April 2010): pg. 123-133. DOI. This article is (c) Palgrave Macmillan and permission has been granted for this version to appear in e-Publications@Marquette. Palgrave Macmillan does not grant permission for this article to be further copied/distributed or hosted elsewhere without the express permission from Palgrave Macmillan. 
Among subjects who received the APA guideline, when the ad presented two symptoms, subjects exposed to common symptoms did not report a higher risk perception $\left[t(63.00)=0.56, P=0.58, M_{\text {two- }}\right.$ common-APA $\left.=29.53, \mathrm{SD}=25.47 ; M_{\mathrm{two} \text {-uncommon-APA }}=25.91, \mathrm{SD}=26.32\right]$, but reported stronger consultation intention $[t(294)=2.41, P=0.02$, $\left.M_{\mathrm{two} \text {-common-APA }}=2.72, \mathrm{SD}=1.75 ; M_{\mathrm{two} \text {-uncommon-APA }}=1.85, \mathrm{SD}=1.35\right]$ than those exposed to uncommon symptoms. When five symptoms were presented, symptom type did not lead to a significant difference in risk perception $\left[t(69.90)=0.09, P=0.93, M_{\text {five-common-APA }}=20.19\right.$, $\left.\mathrm{SD}=20.77 ; M_{\text {five-uncommon }}-\mathrm{APA}=20.64, \mathrm{SD}=19.98\right]$ or consultation intention $\left[t(294)=0.59, P=0.57, M_{\text {five-common-APA }}=2.00, S D=1.35\right.$; $\left.M_{\text {five-uncommon-APA }}=2.19, \mathrm{SD}=1.43\right]$.

\section{Discussion}

While consumers ' perceived risk of a disease and engagement in preventive and remedial actions are likely formed through multiple sources of influence, this study focused on the effects of exposure to specific content elements strategically placed in DTC advertising. Based on the framework of representative heuristic, we suggested college students ' exposure to the APA diagnostic guideline has potential to reduce their perceived lifetime risk of depression and intention to consult a health professional to discuss depression. The findings of this study revealed when the ad mentioned a relatively long list of symptoms, exposure to the diagnostic guideline reduced risk perception and consultation intention significantly, whereas in the presence of a short list of symptoms, the APA guideline had minimal impact.

Putsis and Dhar ${ }^{19}$ suggested brand promotions produce the expansion of a new product category in addition to brand switching. This suggests promotions are not necessarily a zero-sum game. Donohue and Berndt ${ }^{2}$ found DTC advertising for antidepressants increased the number of depression diagnosis and requests for antidepressant treatment, implying DTC advertising contributed to the expansion of the antidepressant market. The findings of this study have implications for how practitioners can use DTC advertising in an effective and socially responsible way to expand a drug category. 
How can advertising practitioners use DTC advertising to expand a drug category? From a marketing perspective, one may assume that including a diagnostic guideline such as the APA guideline regarding the appropriate diagnosis of clinical depression will always be detrimental to the growth of a drug category, because it makes the health problem seem more difficult to develop. This assumption may present an ethical dilemma for DTC advertising practitioners, because from the perspective of consumer welfare, presenting a diagnostic guideline would enable consumers to have more accurate and balanced information about their health problems.

The current study illuminates how practitioners can resolve this dilemma by showing that a diagnostic guideline's capability to reduce consumer risk perception of a disease was significantly reduced when the amount of symptom-related information was small. That is, the guideline significantly reduced consumer risk perception of depression only when the ad presented a large amount of symptom-related information. Therefore, when practitioners present a diagnostic guideline to avoid the criticism that DTC ads omit valuable health information and therefore offer limited educational value, ${ }^{20}$ they should consider reducing the amount of information in the ad about the symptoms of the health problem.

The findings also have implications for consumer health. If some content elements of DTC advertising can influence consumers ' perceived risk of diseases and intention for health-related behaviors, would the influence contribute to consumer health? To address the question, we conceptualized the following three possible situations.

Situation 1: Consumers have underrated perception of the risk of depression, and exposure to the content elements leads them to have more realistic perception.

Situation 2: Consumers have overrated perception of the risk of depression, and exposure to the content elements leads them to have further inflated perception.

Situation 3: Consumers' perception may be more or less evenly split around the figures presented by the epidemiological data, and exposure to the content elements

Journal of Medical Marketing, Vol. 10, No. 2 (April 2010): pg. 123-133. DOI. This article is (C) Palgrave Macmillan and permission has been granted for this version to appear in e-Publications@Marquette. Palgrave Macmillan does not grant permission for this article to be further copied/distributed or hosted elsewhere without the express permission from Palgrave Macmillan. 
NOT THE PUBLISHED VERSION; this is the author's final, peer-reviewed manuscript. The published version may be accessed by following the link in the citation at the bottom of the page.

may drive risk perception to be either more realistic or overrated.

The effects may contribute to public health in the first situation, whereas the second situation may indicate a negative consequence. Interpreting the third situation is more complex.

Our data for women indicated the first situation, as females from the control group perceived their lifetime risk to be 20.06 (SD = 15.74) while the real lifetime risk of depression for women is 25 percent. ${ }^{16-17}$ The data indicated the second situation for men, as males from the control group perceived their lifetime depression risk to be 17.83 percent $(S D=23.53$ ) while the real lifetime risk of depression for men is 12 percent. ${ }^{16-17}$ For men, therefore, exposure to combinations of content elements in DTC antidepressant advertising can drive their perceived lifetime risk of depression to be significantly more inflated than their actual lifetime risk.

For this reason, some may argue DTC antidepressant advertising may have negative social consequences among men. However, depending on the health problem, we suggest the potential of DTC advertising to produce unrealistically high risk perception may result in contributing to consumer welfare. For instance, considering depression is a largely under-treated disease, ${ }^{7}$ the power of DTC antidepressant advertising to raise consumer perception of the risk of depression should be considered as an effective and socially beneficial means to detect potential depressive patients and encourage them to seek professional help.

\section{Limitations and Suggestions for Future Research}

The current study has a number of limitations. First, this study is based on a convenient sample of college students. Therefore, the results may not generalize to college-age people or the general consumer population. Therefore, future researchers may explore how the results may be replicated or vary across various segments of the population (for example, Asian Americans, Hispanic-Americans, versus white Americans), research settings (for example, laboratory experiment versus field experiment), and a variety of disease categories. Second, the experimental stimuli were entirely text-based

Journal of Medical Marketing, Vol. 10, No. 2 (April 2010): pg. 123-133. DOI. This article is (C Palgrave Macmillan and permission has been granted for this version to appear in e-Publications@Marquette. Palgrave Macmillan does not grant permission for this article to be further copied/distributed or hosted elsewhere without the express permission from Palgrave Macmillan. 
in order for the effective manipulations of the content elements. Even though similar approaches have been used in previous research, ${ }^{15,21}$ it would be meaningful to replicate the findings using more realistic versions of antidepressant advertisements. Another issue is whether the findings generalize over a longer period of time.

The study presented the stimulus and immediately measured risk perception and consultation intention. As Davis and Meader ${ }^{21}$ suggested, it will be worth exploring if the effects of exposure to the message elements endure over longer periods of time. Future studies may also address the possibility that motivation, ability and opportunity for information processing may change the patterns of interactions observed, as high-elaboration reduces consumers ' dependence on heuristic information processing for judgment making. Therefore, consumers under a high-elaboration condition may be less subject to the influence of the representativeness heuristic.

\section{References}

1. Iizuka, T. and Jin, G. Z. (2005) The effect of prescription drug advertising on doctor visits. Journal of Economics \& Management Strategy 14 (3): 701-727.

2. Donohue, J. M. and Berndt, E. R. (2004) Effects of direct-toconsumer advertising on medication choice: The case of antidepressants. Journal of Public Policy \& Marketing 23 (2): 115127.

3. Bell, R. A., Kravitz, M. S. and Wilkes, R. L. (1999) Advertisementinduced prescription drug requests: Patients' anticipated reactions to a physician who refuses. The Journal of Family Practice 48 (6): 446-452.

4. Kessler, R. C., Avenevoli, S. and Merikangas, K. R. (2001) Mood disorder in children and adolescents: An epidemiologic perspective. Biological Psychiatry 49: 1002-1014.

5. John, D. R. (1999) Consumer socialization of children: A retrospective look at twenty-five years of research. Journal of Consumer Research 26: 183-213. 
6. Rosenthal, M. B., Berndt, E. R., Donohue, J. M., Frank, R. G. and Epstein, A. M. (2002) Promotion of prescription drugs to consumers. New England Journal of Medicine 346 (7): 498-505.

7. Holmer, A. F. (2002) Direct-to-consumer advertising Strengthening our health care system. New England Journal of Medicine 346: 526-528.

8. Block, L. G. and Keller, P. A. (1998) Beyond protection motivation: An investigative theory of health appeals. Journal of Applied Social Psychology 28 (17): 1584-1608.

9. American Psychiatric Association. (1994) Diagnostic and Statistical Manual of Mental Disorders IV. Washington DC: American Psychiatric Association.

10. Kahneman, D. and Tversky, A. (1972) Subjective probability: A judgment of representativeness. Cognitive Psychology 3 (3): 430-454.

11. Menon, G., Block, L. G. and Ramanathan, S. (2002) We're at as much risk as we are led to believe: Effects of message cues on judgments of health risk. Journal of Consumer Research 28: 533-549.

12. Robinson, J. K., Rigel, D. S. and Amonette, R. A. (1998) What promotes skin self-examination? Journal of American Academy of Dermatology 38: 752-757.

13. Lipkus, I. M., Biradavolu, M., Fenn , K., Keller, P. A. and Rimer, B. K. (2001) Informing women about their breast cancer risks: Truth and consequences . Health Communication 13 (2): 205226.

14. Zung, W. W. K. (1965) A self-rating depression scale. Archives of General Psychology 12: 63-70.

15. Davis, J. J. (2000) Riskier than we think? The relationship between risk statement completeness and perceptions of direct-toconsumer advertised prescription drugs. Journal of Health Communication 5: 349-369.

Journal of Medical Marketing, Vol. 10, No. 2 (April 2010): pg. 123-133. DOI. This article is (c) Palgrave Macmillan and permission has been granted for this version to appear in e-Publications@Marquette. Palgrave Macmillan does not grant permission for this article to be further copied/distributed or hosted elsewhere without the express permission from Palgrave Macmillan. 
16. Kessler, R. C., McGonagle, K. A., Swartz, M., Blazer, D. G. and Nelson, C. B. (1993) Sex and depression in the National Comorbidity Survey I: Lifetime prevalence, chronicity and recurrence. Journal of Affective Disorders 29: 85-96.

17. Kessler, R. C., McGonagle, K. A. and Zhao, S. (1994) Lifetime and 12-month prevalence of DSM-psychiatric disorders in the United States: Results from the national comorbidity study. Archives of General Psychiatry 51: 8-19.

18. Raghubir, P. and Menon, G. (2005) Depressed or just blue?: The persuasive effects of a self-diagnosis inventory . Journal of Applied Social Psychology 35 (12): 2535-2559.

19. Putsis, W. P. and Dhar, R. (2001) An empirical analysis of the determinants of category expenditure. Journal of Business Research 52 (3): 277-291.

20. Bell , R. A., Wilkes, M. S. and Kravitz, R. L. (2000) The educational value of consumer-targeted prescription drug print advertising . The Journal of Family Practice 49 (12): 1092-1098.

21. Davis, J. J. and Meader, A. (2009) Beyond content analysis: Assessing fair balance in DTC pharmaceutical advertising. Journal of Medical Marketing 9 (1): 57-66. 
NOT THE PUBLISHED VERSION; this is the author's final, peer-reviewed manuscript. The published version may be accessed by following the link in the citation at the bottom of the page.

\section{Appendix}

Table 1: MANOVA Results for Risk Perception and Consultation Intention

\begin{tabular}{lcccccc}
\hline Independent variable & Wilks' $\Lambda$ & $F$ & $H d f$ & Error df & $P$ & $\eta_{p}^{2}$ \\
\hline Exposure to the APA guideline & 0.98 & 2.24 & 2 & 264 & 0.11 & 0.017 \\
Type of symptoms & 0.99 & 1.36 & 2 & 264 & 0.26 & 0.010 \\
Number of symptoms & 0.99 & 1.53 & 2 & 264 & 0.22 & 0.011 \\
APA $\times$ Type & 0.98 & 2.73 & 2 & 264 & 0.07 & 0.020 \\
APA $\times$ Number & 0.96 & 4.92 & 2 & 264 & 0.01 & 0.036 \\
Type $\times$ Number & 0.99 & 2.04 & 2 & 264 & 0.13 & 0.015 \\
APA $\times$ Type $\times$ Number & 1.00 & 0.49 & 2 & 264 & 0.61 & 0.004 \\
\hline
\end{tabular}

Table 2: Mixed MANOVA Results for Risk Perception and Help-seeking Intention

\begin{tabular}{lcccccc}
\hline Effect & Wilks' $\Lambda$ & $F$ & $H$ df & Error df & $P$ & $\eta_{p}^{2}$ \\
\hline ws & 1.00 & 1.35 & 1 & 265 & 0.25 & 0.005 \\
ws $\times$ Exposure to the APA guideline & 1.00 & 0.77 & 1 & 265 & 0.38 & 0.003 \\
ws $\times$ Type of symptoms & 1.00 & 1.44 & 1 & 265 & 0.23 & 0.005 \\
ws $\times$ Number of symptoms & 0.99 & 2.22 & 1 & 265 & 0.14 & 0.008 \\
ws $\times$ APA $\times$ Type & 0.98 & 5.31 & 1 & 265 & 0.02 & 0.020 \\
ws $\times$ APA $\times$ Number & 1.00 & 0.01 & 1 & 265 & 0.92 & 0.000 \\
ws $\times$ Type $\times$ Number & 0.99 & 1.84 & 1 & 265 & 0.18 & 0.007 \\
ws $\times$ APA $\times$ Type $\times$ Number & 1.00 & 0.28 & 1 & 265 & 0.60 & 0.001 \\
\hline
\end{tabular}

ws is a within-subjects factor including risk perception and consultation intention.

Journal of Medical Marketing, Vol. 10, No. 2 (April 2010): pg. 123-133. DOI. This article is (C) Palgrave Macmillan and permission has been granted for this version to appear in e-Publications@Marquette. Palgrave Macmillan does not grant permission for this article to be further copied/distributed or hosted elsewhere without the express permission from Palgrave Macmillan. 